\title{
UNRUPTURED PREGNANCY IN A NON-COMMUNICATING RUDIMENTARY HORN OF A UNICORNUATE UTERUS - A CASE REPORT
}

\author{
A.M. Famida ${ }^{1}$, Sailatha Ramanujam ${ }^{2}$, A.P. Nalini ${ }^{3}$
}

\section{HOW TO CITE THIS ARTICLE:}

AM Famida, Sailatha Ramanujam, AP Nalini. "Unruptured pregnancy in a non-communicating rudimentary horn of a unicornuate uterus - a case report". Journal of Evolution of Medical and Dental Sciences 2013; Vol2, Issue 36, September 9; Page: 6857-6860.

ABSTRACT: Pregnancy in the rudimentary horn is a rare form of ectopic pregnancy and carries grave consequences for the mother and foetus. $90 \%$ of them present with intra peritoneal haemorrhage in the $2^{\text {nd }}$ trimester due to rupture of the horn. We present a case report of a $19 \mathrm{yr}$ old unmarried primi gravida at 16 weeks of unruptured pregnancy in the rudimentary horn. Laparotomy was done and the rudimentary horn with the unruptured pregnancy was excised. Postop recovery has been uneventful.

KEYWORDS: Unruptured Pregnancy, Rudimentary Horn, Unicornuate Uterus.

INTRODUCTION: Pregnancy in a rudimentary horn of unicornuate uterus is rare. ${ }^{1}$ An incidence of 1 in 76,000 - 1,50,000 pregnancies is reported in the literature. ${ }^{2,3} 90 \%$ of them culminate in rupture during $2^{\text {nd }}$ trimester. Pre-rupture diagnosis is unusual and challenging but possible with a high index of suspicion in the early pregnancy and the role of USG in the accurate diagnosis is highlighted.

CASE PRESENTATION: A 19 yr old unmarried girl at 16 weeks of pregnancy was admitted for termination. The termination of pregnancy was attempted twice with tablet misoprostol on two consecutive days. When the attempts failed, she was referred to us. A hysterotomy was planned. Her basal blood investigations were within normal limits. An USG examination showed a SLIUG corresponding to 16-17 weeks (Fig-1).

As planned, patient taken up for hysterotomy under spinal anaesthesia. To our surprise, a normal looking uterus with a normal fallopian tube and ovary attached at its cornua was seen on the right side while the pregnancy was actually in the rudimentary horn, which was enlarged to $15 \mathrm{X} 12$ $\mathrm{cm}$, thin walled, attached to the uterus at its left lower $1 / 3^{\text {rd }}$ by a fibrous band (Fig-2). The left normal looking tube and ovary was attached to the rudimentary horn.

An incision was made in the horn and a dead foetus expelled out. The placenta was found adherent to the thin myometrial wall of the rudimentary horn. The horn with its tube and ovary was excised. There was no communication noted with the uterine cavity. Post-op period has been uneventful.

DISCUSSION: Unicornuate uterus results from the failure in the development of one of the paramesonephric ducts either partially or completely. Partial development of one of the ducts gives rise to a rudimentary uterine horn. As per the revised classification for mullerian anomalies given by the American Society of Reproductive Medicine, unicornuate uterus is a type 2 classification with unilateral hypoplasia or agenesis ${ }^{4}$. It can be further sub classified into communicating, noncommunicating (83-90\%), no cavity and no horn. Condition may be associated with dysmenorrhoea 
and endometriosis.

Pregnancy in a non-communicating rudimentary horn occurs through the transperitoneal migration of the spermatozoon or the fertilized ovum, as evidenced by the $8 \%$ prevalence of a corpus luteum on the side contralateral to the rudimentary horn containing the pregnancy. In most of the cases the pregnancy in the rudimentary horn leads to spontaneous abortion, malpresentation, preterm labour, intrauterine growth restriction. The most dreaded complication is the massive intraperitoneal haemorrhage due to rupture of the horn which can be life threatening to the mother. The usual outcome of the rudimentary horn pregnancy is, rupture in $2^{\text {nd }}$ trimester in about $90 \%$ of cases with foetal demise which can be catastrophic ${ }^{5}$. Unlike tubal ectopic pregnancy, bleeding is more severe in rupture of rudimentary horn, as the uterine wall is much thicker and more vascular. The uterine rupture associated with rudimentary horn was first reported in 1669 by Mauriceau and Vassal. The timing of rupture varies from 5-35 (avg 21.5) weeks depending on the horn musculature and its ability to hypertrophy and dilate. Maternal mortality due to rupture was $47.6 \%$ before 1990 , but no case of maternal death has been reported since 1960.6 Few cases of pregnancies with late or false diagnosis which have progressed to $3^{\text {rd }}$ trimester resulting in live births have been reported. ${ }^{7}$ Among these neonatal survivability was only $6 \% .{ }^{7}$

As the consequence of rupture can cause significant mortality and morbidity, early diagnosis is essential for management. However the pre rupture diagnosis of rudimentary horn pregnancy is challenging. A careful ultrasound in the $1^{\text {st }}$ trimester with a high index of suspicion, one should be able to make a diagnosis of pregnancy in the rudimentary horn. Tsafrir et al has proposed set of criteria for diagnosis of pregnancy in the rudimentary horn: (1) A pseudo pattern of asymmetrical bicornuate uterus; (2) Absent visual continuity of tissue surrounding the gestational sac and the uterine cervix; (3) Presence of myometrial tissue surrounding the gestational sac. ${ }^{8}$ The sensitivity of the ultrasound is only $26 \%$ and the sensitivity decreases as the pregnancy advances. ${ }^{9}$ In such cases MRI is very useful, not only in confirming the diagnosis, but, also helps in planning the surgery. Tubal pregnancy, cornual pregnancy, and abdominal pregnancy are common sonographic and clinical misdiagnosis. ${ }^{6}$ It is very difficult to establish diagnosis in second trimester due to lack of definitive clinical criteria.

The traditional and established treatment for rudimentary horn pregnancy is surgical removal of the pregnant horn even in unruptured case to prevent rupture and recurrent rudimentary horn pregnancy. ${ }^{6}$ We performed an emergency laparotomy and successfully excised the rudimentary horn along with ipsilateral salpingectomy.

Laparoscopic excision of the rudimentary horn pregnancy prior to rupture has been done successfully since last two decades. ${ }^{10}$ Renal anomalies are found in $36 \%$ of cases, hence it is mandatory to assess these women prior to surgery. Medical management with methotrexate during early pregnancy in the rudimentary horn has also been used successfully. ${ }^{11}$

CONCLUSION: Rudimentary horn pregnancy is a rare complication which carries grave risk to the mother. More than $90 \%$ of the cases present in second trimester with intraperitoneal haemorrhage due to rupture of the horn. Diagnosis prior to rupture should be the concern in early pregnancy with either ultrasound or MRI to prevent life threatening complications. The recent trend is to do laparoscopic excision of the rudimentary horn. Laparotomy is still an option, when the patient is in shock. 


\section{REFERENCES:}

1. Tufail A, Hasmi HA; Ruptured ectopic pregnancy in rudimentary horn of the uterus. J Coll Physicians Surg Pak. 2007, 17:105-106.

2. Ural SH, Artal R: Third trimester rudimentary horn pregnancy: A case report. J Reprod Med. 1998, 37: 919-921.

3. Nahum G: Rudimentary uterine horn pregnancy; case report on surviving twins delivered 8 days apart J Reprod Med.1997,42:525-532.

4. Reichman D, Laufer MR, Robinson BK, Pregnancy outcomes in unicornuate uteri; a review. Fertil Steril 2009; 91:1886-94.

5. Liu MM: Unicornuate uterus with rudimentary horn. Int J Gynaecol Obstet. 1994, 44: 149153

6. Nahum G: Rudimentary horn pregnancy: the 20th century worldwide experience of 588 cases. J Reprod Med. 2002, 47:151-163.

7. Jin Woo Shin,Hai Joong Kim: Case of live birth in a non communicating rudimentary horn pregnancy.J Obstet Gynaecol Res. 2005,31:329-331.

8. Tsafrir A, Rojansky N, Sela HY, et al: Rudimentary horn Pregnancy: first trimester prerupture sonographic diagnosisand confirmation by magnetic resonance imaging. J Ultrasound Med, 2005, 24:219-223.

9. Yasmin Jayasinghe, Ajay Rane, Harry Stalewski, et al: The presentation and early diagnosis of the rudimentary horn. Obstet Gynaecol. 2005, 105:1456-1467.

10. Sharma D, Usha MG, Gaikwad R, Sudha S. Laparoscopic resection of unruptured rudimentary horn pregnancy. Int J Reprod Contracept Obstet Gynecol 2013; 2:95-8.

11. Edelman AB, Jensen JT, Lee DM, Nichols MD. Successful medical abortion of a pregnancy within a non-communicating rudimentary uterine horn. Am J Obstet Gynecol 2003;189:8867.

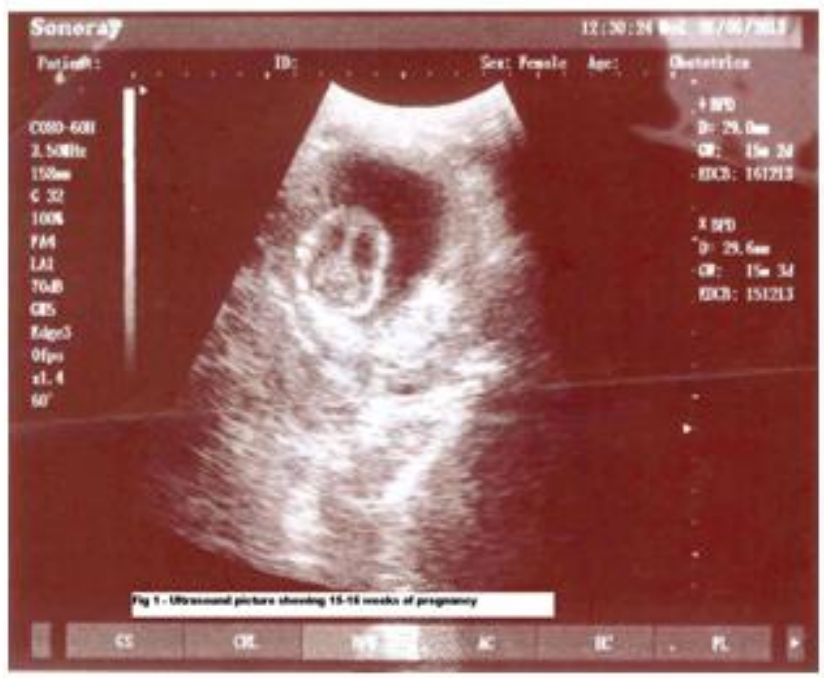

Fig 1 - Ultrasound picture showing 16-17 weeks of pregnancy 


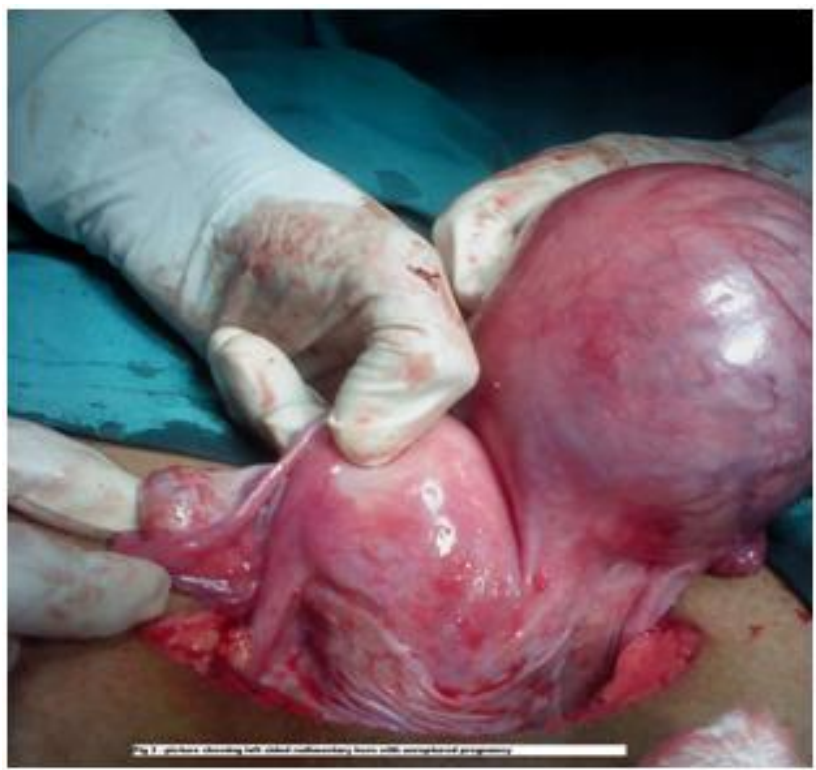

Fig 2 - Picture showing left sided rudimentary horn with unruptured pregnancy

\section{AUTHORS:}

1. A.M. Famida

2. Sailatha Ramanujam

3. A.P. Nalini

\section{PARTICULARS OF CONTRIBUTORS:}

1. Professor, Department of Obstetrics and Gynaecology, Chettinad Health and Research Institute, Rajiv Gandhi Salai, Kelambakkam, Kanchipuram Dist, TN.

2. Assistant Professor, Department of Obstetrics and Gynaecology, Chettinad Health and Research Institute, Rajiv Gandhi Salai, Kelambakkam, Kanchipuram Dist, TN.
3. Professor, Department of Obstetrics and Gynaecology, Chettinad Health and Research Institute, Rajiv Gandhi Salai, Kelambakkam, Kanchipuram Dist, TN.

\section{NAME ADDRESS EMAIL ID OF THE CORRESPONDING AUTHOR:}

Dr. A.M. Famida,

10A, Karpagambal Nagar,

$2^{\text {nd }}$ Street, Ramapuram,

Chennai- 600089.

Email - famida.balaguru@gmail.com

Date of Submission: 17/08/2013.

Date of Peer Review: 18/08/2013.

Date of Acceptance: 28/08/2013.

Date of Publishing: 03/09/2013 